This is the accepted manuscript (post-print version) of the article. As regards to content, the post-print version is identical to the final published version, but there may be differences in typography, layout, and copyediting. Please cite the published version:

Liebst, Lasse S., Richard Philpot, Marie B. Heinskou, and Marie R. Lindegaard. 2018. Samfundsфkonomen, no. 4

\title{
Bystander Intervention in Street Violence: Current Evidence and Implications for Practice
}

Lasse Suonperä Liebst, Richard Philpot, Marie Bruvik Heinskou, and Marie Rosenkrantz Lindegaard $^{1}$

\begin{abstract}
In street violence, bystanders are a potential resource for crime prevention, as they tend to be present when the police are absent. This paper describes evidence of bystanders taking an active role in the prevention of violence and considers implications for crime prevention initiatives.
\end{abstract}

\section{Introduction}

How do bystanders react when witnessing violence in public places? Most people may recall cases covered in the media where no one present intervened, and the scientific study of bystander behavior was prompted by one such tragic case: The 1964-rape and murder of the 28-year-old Kitty Genovese in New York, where 37 bystanders allegedly failed to intervene. Two social psychological scholars, Darley and Latané (1968), set out to explain the factors underpinning the bystander apathy observed in this and similar cases. In a series of influential experimental studies, they found that increasing numbers of bystanders present reduced the individual likelihood of intervention. This was described as the 'bystander effect,' and is typically attributed to the psychological process by which additional bystanders diffuse the individual responsibility for helping. That is, "why should I intervene when the others present could do it?" Decades of subsequent research

\footnotetext{
${ }^{1}$ Principal Investigator 'Violence, Bystanders, and...Action!' (Independent Research Fund ref. 6109-00210) and corresponding author: mrl@soc.ku.dk
} 
established the bystander effect as one of the best-replicated findings within social psychology (Manning, Levine, \& Collins, 2007).

Recently, however, this apathetic view of bystanders has been challenged. In a meta-analytical synthesis of the experimentally-based bystander effect research field, Fischer et al. (2011) showed that the bystander effect does not generalize to dangerous emergencies. When comparing bystander helping in low versus high danger conditions, they found that the bystander effect attenuated, or even reversed, in simulations of highdanger. This suggests that bystanders intervene when it really matters, and that the presence of others does not diffuse the responsibility for helping. Rather, in dangerous situations, additional bystanders may offer a welcome support that increases the likelihood of helping. This latter 'reversed bystander effect' is meaningful from the standpoint of the intervener: "I can intervene because there are others to help me if this dangerous situation gets out of hand."

Fischer and colleagues have since verified the existence of the reversed bystander effect in field experiments simulating aggressive emergencies (Fischer \& Greitemeyer, 2013). Adding to this, recent reassessments of the Kitty Genovese case document that several bystanders did in fact do something to help, as expected under the reversed bystander effect hypothesis (Manning et al., 2007). Taken together, this leaves us, both at the meta-analytical and anecdotal level of knowledge, with a more optimistic and agential view of bystanders.

These recent findings not only reframe the role of bystanders within the psychological literature, but are also of importance for the parallel criminological work that conceptualizes bystanders as 'guardians' (Cohen \& Felson, 1979). Here, it is argued that the mere presence of bystanders has a crime preventive effect, with bystander presence making it more difficult and risky from the perspective of the offender to commit a crime. Although this situational approach is effective in deterring 'cold-headed' crimes, (e.g., robberies, burglaries, petty theft), it may be less effective against 'hot-headed' crimes, such as street violent assaults (Hayward, 2007). Moving beyond a mere focus on bystander presence as a deterrent to crime, in this paper, we suggest that bystander actions may offer new avenues for behavior-based crime prevention initiatives.

Alongside the meta-analytical work highlighting the importance of danger for bystander intervention, studies more recently examine bystander involvement in the 
dangerous setting of real-life public violence. Here, the methods employed include assessments of police case file descriptions of public violent assaults (Heinskou \& Liebst, 2017), interviews with bystanders (Levine, Lowe, Best, \& Heim, 2012), on-site observations of bystander involvement (Parks, Osgood, Felson, Wells, \& Graham, 2013), and video observations of street violence using surveillance camera footage (Levine, Taylor, \& Best, 2011; Liebst, Heinskou, \& Ejbye-Ernst, 2018; Philpot, 2017). The latter video-based method, offers a unique possibility to systematically study how violent interactions unfold chronologically and how bystanders shape the ongoing situation (Lindegaard \& Bernasco, 2018).

\section{How typical is intervention in street violence?}

The impression left by much of the existing bystander and guardianship literature is that those witnessing a real-life emergency rarely intervene to help (Manning et al., 2007). However, a recent systematic assessment of 500 police-reported public assaults in Copenhagen, Denmark, showed that at least one bystander intervened to help in approximately three-out-of-four cases (Heinskou \& Liebst, 2017). The majority of these de-escalatory interventions were physical in nature and included behaviors such as holding back an aggressive individual or blocking conflict parties. This high intervention rate may be underestimated, however, given that police case files are not specifically interested in the behavior of bystanders and may exclude conflicts that did not escalate because of successful bystander intervention. Using a cross-national video sample of both reported, and, crucially, non-reported public assaults, Philpot and colleagues (2019) found that at least one bystander (but typically three or four) carried out helping interventions in nineout-of-ten of the aggressive incidents. Further, this study found similar rates of deescalation across three national contexts (the United Kingdom, the Netherlands, and South Africa). Taken together, and in contrast to established ideas, these studies evidence that the rate of real-life intervention in public assaults is very high.

\section{How do people intervene?}

Within the traditional bystander literature field, there exists a binary understanding of bystander action - as passive or actively helpful. However, by studying the actual behaviors of bystanders, this dichotomous distinction is superseded by a multidimensional 
understanding of bystander roles and action types. For example, de-escalatory helping may be expressed in a variety of forms: one can intervene in a physical manner by separating or blocking the conflict parties; in a non-physical way with pacifying gesturing or verbal pleas to calm down; or be directed towards third-parties, such as calling the police or asking a friend or bouncer to help (Heinskou \& Liebst, 2017; Levine et al., 2011).

In addition to the de-escalatory helping measured in the above studies, bystanders may also intervene in escalatory manners. Bystanders may fight on behalf of their group, or even, paradoxically, use aggression with the purpose to de-escalate the conflict (Levine et al., 2012; Levine et al., 2011; Parks et al., 2013). Besides intervention into ongoing conflicts, video observational studies document that bystanders provide emotional care and stress-reducing touching to victims of violence post-conflict (Liebst, Philpot, Ejbye-Ernst, Bernasco, et al., 2018; Lindegaard et al., 2017). Bystander helping, both in the ongoing conflict and post-conflict, are typically coordinated in a collective effort between multiple bystanders (Bloch, Liebst, Poder, Christensen, \& Heinskou, 2018; Levine et al., 2011). For example, Bloch and colleagues describe post-conflict care as a coordinated task performed by a 'caring collective,' in which different bystanders take on different roles - e.g., one individual fetches paper towels in a nearby shop, while another comforts the victim. Note, that similar bystander coordination is also observed in nonviolent medical emergencies (Linderoth et al., 2015).

\section{Why do people intervene?}

To date, the most common explanation for bystander non-intervention is the increased number of those present - i.e., the bystander effect. However, as aforementioned, the bystander effect may not generalize to dangerous emergencies, in which additional bystanders may promote intervention-i.e., the reversed bystander effect (Fischer et al., 2011). This latter finding is in line with a number of video observational studies recording higher levels of intervention in more populated emergencies (Levine et al., 2011; Lindegaard et al., 2017; Philpot, 2017). A Danish video-based study of violent public assaults, however, found that the individual propensity to intervene decreased with additional bystander presence, similar to the prediction of the classical bystander effect (Liebst, Philpot, et al., 2018; see also Phillips \& Cooney, 2005). Taken together, the 
evidence remains mixed when assessing the role of bystander numbers in real-life intervention contexts. Conversely, the high intervention rate consistently found in real-life violent settings indicates that danger is an important contextual predictor of intervention. However, a systematic comparison of real-life bystander intervention in non-dangerous versus dangerous/violent contexts is needed to ascertain the validity and strength of this association.

A uniformly robust finding is that social group membership with a conflict party strongly predicts bystander intervention. Specifically, if the bystander identifies as being a member of the same social group as the victim or perpetrator, it is more likely that the bystander provides help (for a review, Levine \& Manning, 2013). For example, Levine and colleagues (2012) found that bystanders are motivated to help victims whom they personally know - sometimes by fighting on their behalf, but most typically, through the de-escalatory 'self-policing' of their unruly friends. Extending this research, Liebst and colleagues examined the strength of social group membership as a predictor of bystander intervention in ongoing conflicts (Liebst, Philpot, Ejbye-Ernst, Dausel, et al., 2018). The researchers used video observational data from public assaults in Copenhagen, and examined whether the number of individuals present or social group membership bestpredicted bystander involvement. Social group membership was determined using nonverbal behavioral cues, such as collective behavior-in-concert and bodily proximity (Afifi \& Johnson, 2005), which were then validated against police case file descriptions. Results showed that group membership outcompeted bystander presence as the main predictor of intervention. A similar result was recorded when assessing consolatory helping in the aftermath of the street assaults, with social group membership again the dominant predictor (Liebst, Philpot, Ejbye-Ernst, Bernasco, et al., 2018). Moreover, this finding is consistent with Lindegaard and colleagues' (2017) previous study, which found that in the aftermath of commercial robberies, employees were, compared to members of the public, disproportionately more likely to console fellow victimized employees.

While social group membership is now established as a key predictor of bystander intervention, Liebst et al. (2018) also associate this factor to an elevated risk of bystander victimization when intervening to help. In this study, which also relied on police-reported video data of Copenhagen assaults, the overall risk of victimization was quite low (at $12 \%$ for de-escalatory interveners, and $18 \%$ for de-escalatory/escalatory 
mixed interveners). Further, these victimizations were typically low in severity-for example, being pushed away once by the perpetrator. The authors examined two potential risk factors of bystander victimization: whether it is more dangerous to intervene into severe conflicts, or whether it is more dangerous to intervene when knowing a conflict party. Results found no association between conflict severity and bystander victimization, but did identify social group membership as an elevated risk factor. Theoretically, this suggests that an intervening friend is not perceived as a neutral party by perpetrators, but as a partisan who is an eligible target of aggression.

\section{How helpful are interventions?}

Perhaps the most pertinent question is whether the bystander interventions are helpful in de-escalating conflicts-yet, surprisingly, little systematic evidence has addressed this question. This omission is, in part, due to the circumstance that the literature until recently has assumed bystanders are largely passive. Further adding to this issue, it remains statistically difficult to establish casual dynamics from observational data. However, in our view, based on over 500 qualitative observations of real-life captured assaults, bystanders play a key role in successfully ceasing conflicts. This aligns with the few studies examining the outcome of bystander actions. In a sequential video analysis of street violence in the United Kingdom, Levine, Best and Taylor (2011) indicated that cumulative interventions of multiple bystanders are associated with reduced conflict severity. This finding suggests, in line with Bloch et al. (2018), that cooperation between bystanders makes intervention successful. More recently, Philpot (2017) examined the distinction between bystander interventions aimed at one conflict party (i.e., the victim or the perpetrator) or aimed at both conflict parties. He found that de-escalatory interventions targeted at both conflict parties were associated with a lower overall severity than those aimed at sole individuals. This study, however, was not able to untangle the causal dynamics and should be interpreted with caution. Future research should prioritize systematic statistical studies of the helpfulness of bystander intervention.

\section{Discussion and implications}

Current advice from the Danish Crime Prevention Council (2002) highlights that bystanders witnessing street violence may easily escalate the situation or become a victim 
themselves by intervening. Thus, it is suggested that bystanders stay at a distance from the conflict while making their presence known as to indirectly deter the offender. These recommendations fall in line with the criminological notion of bystanders as guardians (Cohen \& Felson, 1979), in which it is the mere presence of bystanders that has a crime preventive effect. The recent evidence presented, however, advocates an update of this advice. Real-life data shows that bystanders are not passive or merely observant during street violence. Rather in the vast majority of conflicts at least one, but typically several bystanders, are physically intervening to help. Given this high intervention rate, it is important to provide guidance on how to intervene effectively and safely. Further, there is no empirical basis for the view that bystander intervention leads to escalation. To the contrary, evidence suggests that direct physical intervention is successful in de-escalating conflict. Further, the risk of bystander victimization and the severity of victimization are both fairly low, in particular for intervening strangers.

The recent advances in bystander research may also inform urban and police crime prevention strategies. Within urban planning theory, there remains a debate whether large amounts of individuals on the street are detrimental or beneficial to public safety. On the one hand, some scholars suggest that more populated streets offer a greater possibility for interpersonal friction and conflict (see Townsley \& Grimshaw, 2013), without anyone feeling obliged to taking responsibility for the place (Newman, 1972). This leads to recommendations that large groups should be split up by authorities and that street layouts should be designed to minimize pedestrian co-presence and traffic. On the other hand, some argue that the co-presence of individuals provides 'safety in numbers,' because there are more people present to intervene if necessary (Hillier, 2004). The literature assessed would suggest an important balance between the two arguments: While there is little doubt that the number of people present is a background condition for the emergence of violent hotspots, this increased presence also provides more bystanders who will actively intervene to help in cases of violence. Future research should look beyond the positive association between co-presence and violence and examine the counter-balance association of increased bystander co-presence and more helping.

The finding that typically multiple bystanders coordinate to de-escalate conflicts has important implications for how police forces manage groups in public settings - for example, in nightlife drinking areas, where groups tend to be approached as 
instigating rather than regulating violence (Levine et al., 2012). The present evidence shows that members of the public are effectively able to 'self-police' conflicts, without the necessary involvement of police authorities. This readily available bystander resource is not only cost-efficient, but may in certain situations be preferred (e.g., those events characterized by tensions between the police and the public) (Eck, 2015). The important point, however, is that official policing and informal self-policing are not mutually exclusive efforts. Bystanders have an established role as witnesses in legal proceedings of street violence. In our view, besides this role, bystanders should be further recognized as helpful actors in the conflict itself, where they can provide valuable assistance before the arrival of the police.

With the success of bystander intervention programs addressing sexual violence on campuses (Jouriles, Krauss, Vu, Banyard, \& McDonald, 2018), it is further recommended that crime prevention agencies engage members of the public more directly in bystander efforts targeting street violence. Such initiatives should inform the public that bystander intervention is commonplace, that it is likely to help, without exposing the intervener to great risk. Knowing that social group members are already highly likely to intervene, such initiatives should aim towards engaging even more strangers. This increased engagement is welcome from the perspective of the victim, but is also preferable given that strangers are exposed to the lowest risk of bystander victimization. Finally, such campaign may also alleviate the widespread fear that public strangers are a source of potential danger or are apathetic when witnessing violent crimes (Hale, 1996).

\section{References}

Afifi, W. A., \& Johnson, M. L. (2005). The nature and function of tie-signs. In V. L. Manusov (Ed.), The sourcebook of nonverbal measures: Going beyond words (pp. 189-198). New Jersey: Psychology Press.

Bloch, C., Liebst, L. S., Poder, P., Christensen, J., \& Heinskou, M. B. (2018). Caring collectives and other forms of bystander helping behavior in violent situations. Current Sociology.

Cohen, L. E., \& Felson, M. (1979). Social change and crime rate trends: A routine activity approach. American Sociological Review, 588-608.

Darley, J. M., \& Latané, B. (1968). Bystander intervention in emergencies: Diffusion of responsibility. Journal of Personality and Social Psychology, 8(4), 377-383.

Eck, J. E. (2015). Who should prevent crime at places? The advantages of regulating place managers and challenges to police services. Policing: A Journal of Policy and Practice, 9(3), 223-233. 
Fischer, P., \& Greitemeyer, T. (2013). The positive bystander effect: Passive bystanders increase helping in situations with high expected negative consequences for the helper. Journal of Social Psychology, 153(1), 1-5.

Fischer, P., Krueger, J. I., Greitemeyer, T., Vogrincic, C., Kastenmüller, A., Frey, D., . . . Kainbacher, M. (2011). The bystander-effect: A meta-analytic review on bystander intervention in dangerous and non-dangerous emergencies. Psychological Bulletin, 137(4), 517-537.

Hale, C. (1996). Fear of crime: A review of the literature. International Review of Victimology, 4(2), 79-150.

Hayward, K. (2007). Situational crime prevention and its discontents: Rational Choice Theory versus the 'culture of now'. Social Policy \& Administration, 41(3), 232250.

Heinskou, M. B., \& Liebst, L. S. (2017). Gadevold. En sociologisk kortlagning af vold $i$ byen. København: Djøf Forlag.

Hillier, B. (2004). Can streets be made safe? Urban Design International, 9(1), 31-45.

Jouriles, E. N., Krauss, A., Vu, N. L., Banyard, V. L., \& McDonald, R. (2018). Bystander programs addressing sexual violence on college campuses: A systematic review and meta-analysis of program outcomes and delivery methods. Journal of American College Health, 1-10.

Levine, M., Lowe, R., Best, R., \& Heim, D. (2012). 'We police it ourselves': Group processes in the escalation and regulation of violence in the night-time economy. European Journal of Social Psychology, 42(7), 924-932.

Levine, M., \& Manning, R. (2013). Social identity, group processes, and helping in emergencies. European Review of Social Psychology, 24(1), 225-251.

Levine, M., Taylor, P. J., \& Best, R. (2011). Third parties, violence, and conflict resolution: The role of group size and collective action in the microregulation of violence. Psychological Science, 22(3), 406-412.

Liebst, L. S., Heinskou, M. B., \& Ejbye-Ernst, P. (2018). On the actual risk of bystander intervention: A statistical study based on naturally occurring violent emergencies. Journal of Research in Crime and Delinquency, 55(1), 27-50.

Liebst, L. S., Philpot, R., Ejbye-Ernst, P., Bernasco, W., Verbeek, P., Heinskou, M. B., . . Lindegaard, M. R. (2018). Consolation in the Aftermath of Violent Public Assaults: Towards an Interaction Ethology of Bystander Emergency Behavior. Paper presented at the Danish Sociological Conference 2018, Esbjerg, Denmark. 25 January 2018.

Liebst, L. S., Philpot, R., Ejbye-Ernst, P., Dausel, K. L., Nicolaisen, M. H., Bernasco, W., ... Lindegaard, M. R. (2018). Bystanders in Real-Life Dangerous Emergencies: Group Relationships Predict Intervention. Paper presented at the Danish Sociological Conference 2018, Esbjerg, Denmark. 25 January 2018.

Lindegaard, M. R., \& Bernasco, W. (2018). Lessons learned from crime caught on camera. Journal of Research in Crime and Delinquency, 55(1), 155-186.

Lindegaard, M. R., Liebst, L. S., Bernasco, W., Heinskou, M. B., Philpot, R., Levine, M., \& Verbeek, P. (2017). Consolation in the aftermath of robberies resembles postaggression consolation in chimpanzees. PloS one, 12(5), e0177725.

Linderoth, G., Hallas, P., Lippert, F. K., Wibrandt, I., Loumann, S., Møller, T. P., \& Østergaard, D. (2015). Challenges in out-of-hospital cardiac arrest-a study combining closed-circuit television (CCTV) and medical emergency calls. Resuscitation, 96, 317-322. 
Manning, R., Levine, M., \& Collins, A. (2007). The Kitty Genovese murder and the social psychology of helping: The parable of the 38 witnesses. American Psychologist, 62(6), 555-562.

Newman, O. (1972). Defensible space: Crime prevention through urban design. New York: Macmillan.

Parks, M. J., Osgood, D. W., Felson, R. B., Wells, S., \& Graham, K. (2013). Third party involvement in barroom conflicts. Aggressive Behavior, 39(4), 257-268.

Phillips, S., \& Cooney, M. (2005). Aiding peace, abetting violence: Third parties and the management of conflict. American Sociological Review, 70(2), 334-354.

Philpot, R. (2017). Beyond the dyad: The role of groups and third-parties in the trajectory of violence. (Doctoral dissertation), University of Exeter, Exeter.

Philpot, R., Liebst, L. S., Levine, M., Bernasco, W., \& Lindegaard, M. R. (2019). Would I be helped? Cross-National CCTV Shows That Intervention Is the Norm in Public Conflicts. American Pshychologist

Townsley, M., \& Grimshaw, R. (2013). The consequences of queueing: Crowding, situational features and aggression in entertainment precincts. Crime Prevention and Community Safety, 15(1), 23-47. 